\title{
Effects of ingestion of tomatoes, tomato juice and tomato purée on contents of lycopene isomers, tocopherols and ascorbic acid in human plasma as well as on lycopene isomer pattern
}

\author{
Kati Fröhlich, Karin Kaufmann, Roland Bitsch and Volker Böhm* \\ Institute of Nutrition, Friedrich Schiller University Jena, Dornburger Strasse 25-29, D-07743 Jena, Germany
}

(Received 8 July 2005 - Revised 25 October 2005 - Accepted 25 October 2005)

\begin{abstract}
Tomatoes are an important part of the diet. Lycopene, the predominant carotenoid in tomatoes, is hypothesised to mainly mediate the health benefits of tomato products. Anticancer activity of tomato products and lycopene has been suggested by numerous studies. The aim of the present study was to investigate the effect of ingestion of three different tomato-based foodstuffs on plasma contents of lycopene, tocopherols and ascorbic acid. Because isomers of lycopene may have different biological activities, a special interest was to look how the lycopene isomer pattern is changed depending on the matrix of tomato products. Following a 2-week depletion phase volunteers ingested $12.5 \mathrm{mg}$ lycopene/d for 4 weeks comprising tomatoes, tomato juice or tomato purée. The basal levels of lycopene in plasma were comparable for all groups and decreased significantly during the 2 weeks of depletion to approximately half of the basal values. Following intervention, plasma lycopene concentration increased significantly. Conversely, supplementation did not significantly affect levels of tocopherols and ascorbic acid in plasma. Regarding isomers of lycopene, the (Z)-lycopene:(all-E)-lycopene plasma isomer ratio was significantly changed during the study for all groups. A remarkable enrichment of the relative contents of (5Z)-lycopene was observed during the depletion period, which supports the hypothesis that lycopene (Z)-isomers are formed within the human body after ingestion of (all-E)-lycopene. After dietary intervention with lycopene-rich products the isomer ratios returned to those observed at the start of the study. Further investigations will clarify the process of isomerisation in more detail.
\end{abstract}

Tomato products: (all-E)-Lycopene: Lycopene (Z)-isomers: Ascorbic acid: Tocopherols: Human bioavailability

Several epidemiological studies have indicated a beneficial effect of tomato consumption in the prevention of some major chronic diseases, such as some types of cancer (Giovannucci et al. 2002) and CVD (Klipstein-Grobusch et al. 2000). One of the major phytochemicals in tomato products contributing to the prevention of cancer is lycopene. Reports from epidemiological studies, studies in animals and cell-culture experiments have suggested that lycopene has anticancerogenic properties (Rao \& Agarwal, 1999; Etminan et al. 2004; Tang et al. 2005). In addition to its antioxidant properties (DiMascio et al. 1989; Böhm et al. 2002), lycopene has also been shown to induce cell-cell communication (Zhang et al. 1991; Stahl et al. 2000), activate phase II enzymes (Breinholt et al. 2000), inhibit tumour cell proliferation (Levy et al. 1995), repress insulin-like growth factor receptor activation (Karas et al. 2000), and improve anti-tumour immune responses (Clinton, 1998). The mechanisms by which lycopene might exert its biological activities are still unknown.

The general structure of lycopene is an aliphatic hydrocarbon with eleven conjugated carbon-carbon double bounds, making it soluble in lipids and red in colour. Being acyclic, lycopene has no vitamin A activity. Recent investigations have shown that lycopene derivatives could activate retinoid receptors. However, the physiological significance has to be shown in future studies (Sharoni et al. 2004). Lycopene from tomatoes and tomatobased foods exists predominantly in the (all-E)-configuration, the thermodynamically most stable form (Porrini et al. 1998). In contrast, various (Z)-isomers account for over $50 \%$ of blood lycopene and for over $75 \%$ of tissue lycopene (Clinton et al. 1996; Ferruzzi et al. 2001). The processes that influence isomer patterns and the mechanisms of interconversion are still an essentially unexplored area of research. Isomerisation of lycopene may have significant consequences since the large three-dimensional differences between these geometric isomers may influence their pharmacological properties (Holloway et al. 2000). Recent investigations using the Trolox equivalent antioxidant capacity assay have shown significantly different antioxidant activity for lycopene isomers depending on the geometrical structure (Böhm et al. 2002).

The aim of the present study was to explore the interrelationships among the intake of different commonly consumed tomato products (tomatoes, tomato juice, tomato purée), plasma lycopene isomer profiles and plasma levels of ascorbic acid and tocopherols. All volunteers were supplied with a daily dosage of $12.5 \mathrm{mg}$ lycopene for 4 weeks after a 2week diet low in lycopene.

\section{Subjects and methods}

Subjects and study design

Seventeen subjects (fourteen women and three men) ranging from 19 to 25 years with a BMI between 19 and $25 \mathrm{~kg} / \mathrm{m}^{2}$ 
participated in the study. They were divided randomly into three groups (tomato group, tomato juice group, tomato purée group). Characteristics of the subjects are summarised in Table 1. The participants were non-smokers and did not take carotenoid supplements or vitamin A supplements. Informed written consent was obtained from each participant and the protocol was approved (ethical vote no. 0913-07/02) by the Ethical Committee of the Friedrich Schiller University Jena at the Medical Faculty (Bachstrasse 18, 07743 Jena, Germany). Subjects were asked to follow precise instructions regarding their diet to limit carotenoid intake without interfering with their own eating habits. All subjects avoided food rich in lycopene such as tomatoes and tomato products, water melons, yellow and red peppers, pink grapefruit, papayas, apricots, guavas, rosehip products and sea-buckthorn products for a 2-week depletion period and the following 4 weeks of intervention. After the depletion period, they ingested $12.5 \mathrm{mg}$ lycopene/d with breakfast for 4 weeks, either from 145-320 g tomatoes/d, 94-101 g tomato juice/d or $25-28 \mathrm{~g}$ tomato purée/d. They were asked to consume tomatoes and tomato products with a small portion of dietary fat (exact amount was not determined) to guarantee the absorption of lycopene. All intervention products (different batches were only available due to the large amounts needed) were purchased in a local store. The lycopene content of the tomato products was analysed before the start of the study, the lycopene content of the tomatoes after each purchase, in order to calculate the equivalent amounts for the participants. Detailed compositions of the tomato products are shown in Table 1.

\section{Collection of blood samples}

Fasting blood samples $(10 \mathrm{ml})$ were withdrawn from the study participants in EDTA tubes before the study (T-2), after the 2 weeks of depletion (T0) and thereafter weekly while supplemented (T1, T2, T3, T4). The blood samples were entrifuged at $5000 \mathrm{rpm}$ for $10 \mathrm{~min}$ at $5^{\circ} \mathrm{C}$. For ascorbic acid analysis, samples of plasma were immediately stabilised

Table 1. The main characteristics of the subjects participating in the study and composition of the supplemented tomato products

(Mean values and standard deviations)

\begin{tabular}{|c|c|c|c|c|c|c|}
\hline & \multicolumn{6}{|c|}{ Group } \\
\hline & \multicolumn{2}{|c|}{ Tomato } & \multicolumn{2}{|c|}{ Tomato juice } & \multicolumn{2}{|c|}{ Tomato purée } \\
\hline & Mean & SD & Mean & SD & Mean & SD \\
\hline \multicolumn{7}{|l|}{ Subjects } \\
\hline$n$ & & 6 & & 6 & & 5 \\
\hline Age (years) & $23 \cdot 0$ & 0.6 & $22 \cdot 8$ & $2 \cdot 2$ & $22 \cdot 4$ & $1 \cdot 7$ \\
\hline Body weight (kg) & $61 \cdot 7$ & $5 \cdot 4$ & $62 \cdot 7$ & $8 \cdot 8$ & $60 \cdot 7$ & $6 \cdot 0$ \\
\hline BMI $\left(\mathrm{kg} / \mathrm{m}^{2}\right)$ & $21 \cdot 7$ & $1 \cdot 7$ & $21 \cdot 4$ & 1.8 & $20 \cdot 4$ & 1.9 \\
\hline \multicolumn{7}{|c|}{ Tomato products } \\
\hline \multicolumn{7}{|c|}{ Total-lycopene $(\mathrm{mg} / 100 \mathrm{~g})$} \\
\hline Minimum & 3.9 & 0.3 & $11 \cdot 5$ & 0.6 & $44 \cdot 4$ & 1.9 \\
\hline Maximum & $8 \cdot 7$ & 0.4 & $12 \cdot 4$ & 0.7 & $50 \cdot 5$ & 3.4 \\
\hline \multicolumn{7}{|c|}{ Ascorbic acid (mg/100 g) } \\
\hline Minimum & $4 \cdot 0$ & 0.1 & $5 \cdot 8$ & 0.2 & 34.5 & 0.7 \\
\hline Maximum & $7 \cdot 2$ & 0.1 & $6 \cdot 7$ & 0.3 & 35.4 & 0.6 \\
\hline \multicolumn{7}{|c|}{ Total tocopherol $(\mu \mathrm{mol} / 100 \mathrm{~g})$} \\
\hline Minimum & 0.34 & 0.01 & $2 \cdot 75$ & 0.06 & $11 \cdot 82$ & 0.90 \\
\hline Maximum & 0.66 & 0.01 & $2 \cdot 87$ & 0.01 & $15 \cdot 23$ & 0.35 \\
\hline
\end{tabular}

For details of subjects and procedures, see p. 734. with TCA. All plasma samples were stored at $-80^{\circ} \mathrm{C}$ until analysis. Blood samples and plasma samples were always handled under subdued light.

\section{Analysis of carotenoids}

Carotenoids were extracted according to Bieri et al. (1985), slightly modified. An equal volume of ethanolic echinenone (kind gift of DSM Nutritional Products, Basel, Switzerland) solution (internal standard) was added to $500 \mu \mathrm{l}$ plasma. The sample was mixed using a vortex for $30 \mathrm{~s}$ before addition of $250 \mu \mathrm{l}$ hexane with $0.1 \%$ butylated hydroxytoluene. The mixture was shaken for $1 \mathrm{~min}$ and centrifuged at $14000 \mathrm{rpm}$ for $2 \mathrm{~min}$. The plasma extraction procedure was performed three times on each sample to ensure total removal of carotenoids. The combined hexane layers were evaporated to dryness using a gentle stream of $\mathrm{N}_{2}$ at $30 \pm 1^{\circ} \mathrm{C}$. The residue was dissolved in $250 \mu \mathrm{l}$ methanol-methyl tert-butylether $(1: 1, \mathrm{v} / \mathrm{v})$, vortexed and centrifuged at $14000 \mathrm{rpm}$ for $4 \mathrm{~min}$. The supernatant fraction was analysed on a $C_{30}(250 \times 4.6 \mathrm{~mm}, 5 \mu \mathrm{m})$ column (YMC Europe, Schermbeck, Germany), preceded by a C18 ProntoSil 120-5-C18 H $(10 \times 4.0 \mathrm{~mm}, 5 \mu \mathrm{m})$ column (Bischoff, Leonberg, Germany) at $23 \pm 1{ }^{\circ} \mathrm{C}$ with diode array detection at $450 \mathrm{~nm}$ (Böhm, 2001). As mobile phase $(1.3 \mathrm{ml} / \mathrm{min})$ the following gradient procedure was used consisting of methanol (solvent A) and methyl tert-butyl ether (solvent B): (1) initial conditions $90 \%$ solvent A and $10 \%$ solvent $\mathrm{B}$; (2) a $55 \mathrm{~min}$ linear gradient to $55 \%$ solvent $\mathrm{B}$; (3) $45 \%$ solvent $\mathrm{A}$ and $55 \%$ solvent B for $5 \mathrm{~min}$; (4) a $10 \mathrm{~min}$ linear gradient to $10 \%$ solvent B. All experiments were carried out under subdued light to prevent photodegradation and isomerisation. Recovery ( $n$ 280) of the internal standard was $96 \pm 12 \%$. (all-E)-Lycopene was identified using reference material, which was a kind gift of DSM Natural Products. (all-E)-Lycopene stock solution in cyclohexane-toluene $(4: 1$, $\mathrm{v} / \mathrm{v}$ ) of $83 \mu \mathrm{g} / \mathrm{ml}$ was prepared and diluted daily 1:100 using a mixture of methanol and methyl tert-butyl ether $(1: 1, \mathrm{v} / \mathrm{v})$ to obtain the working solution. The concentration of the stock solution was checked periodically by using its extinction coefficient (E (1\%, 1 cm): 3450 (n-hexane, $472 \mathrm{~nm}$ ) (Craft et al. 1988)). The lycopene $(Z$ )-isomers were quantified by using the (all-E)-lycopene calibration. Different spectroscopic techniques were used to identify the main lycopene $(Z)$-isomers (Fröhlich et al. 2005).

Tomato products were analysed on their carotenoid contents as recently described elsewhere (Seybold et al. 2004).

\section{Analysis of ascorbic acid}

The content of ascorbic acid was determined by using a spectrophotometrical method according to Speitling et al. (1992). TCA $(300 \mu \mathrm{l})$ was mixed with $200 \mu \mathrm{l}$ of standard solutions (calibration straight line), plasma (which had been already prepared before storage at $-80^{\circ} \mathrm{C}$ ) or distilled water (blank reading value). The reaction mixture was vortexed and centrifuged (12 $000 \mathrm{rpm} ; 5 \mathrm{~min}$ ). Samples of $300 \mu \mathrm{l}$ of the supernatant fraction were mixed with $100 \mu l$ dinitrophenylhydrazine-reagent $(2 \mathrm{~g} / 100 \mathrm{ml})$. The mixture was vortexed again, incubated at $60^{\circ} \mathrm{C}$ on a thermal shaker for $1 \mathrm{~h}$ and cooled on ice for $5 \mathrm{~min}$. Then $400 \mu \mathrm{l}$ sulfuric acid were added to the reaction mixture. After vortexing and keeping in the dark for $20 \mathrm{~min}$, the mixture 
was vortexed once again before spectrophotometrical analysis at $520 \mathrm{~nm}$ against the blank reading.

Tomatoes, tomato juice and tomato purée were analysed on their contents of ascorbic acid as recently described elsewhere (Gahler et al. 2003) by using the spectrophotometrical determination as mentioned earlier for the plasma samples instead of the HPLC determination described there.

\section{Analysis of tocopherols}

Plasma $(500 \mu \mathrm{l})$ was extracted by adding $400 \mu \mathrm{l}$ ethanol containing $0.1 \%$ BHT. The mixture was vortexed for $30 \mathrm{~s}$. After the addition of $400 \mu \mathrm{l}$-hexane the mixture was vortexed again for $1 \mathrm{~min}$ and centrifuged at $14000 \mathrm{rpm}$ for $4 \mathrm{~min}$. The extraction was repeated three times and the combined organic phases were evaporated to dryness under $\mathrm{N}_{2}$ at $30 \pm 1{ }^{\circ} \mathrm{C}$. The residue was dissolved in $1 \mathrm{ml}$ of mobile phase, vortexed and centrifuged (14000 rpm, $4 \mathrm{~min})$. The supernatant fraction was analysed on a diol-column by using n-hexane-methyl tert-butyl ether (96:4, v/v) as mobile phase at a column temperature of $50^{\circ} \mathrm{C}$ with fluorescence detection (Balz et al. 1992). Plasma tocopherol concentration was calculated by means of peak areas of the respective standards: $\alpha$-, $\beta-, \gamma-, \delta$-tocopherols (Calbiochem, Darmstadt, Germany).

Tomato products were analysed on their tocopherol contents as recently described elsewhere (Seybold et al. 2004) by using the same HPLC method as mentioned earlier for the plasma samples.

\section{Statistical analysis}

Results are expressed as means and standard deviations. Differences between variables were tested for significance by using the one-way ANOVA procedure (Tukey) for the basal values and for all other results the general linear model for the two-way ANOVA procedure (SPSS for Windows, release 10.07 (June 2000; SPSS Inc., Chicago, IL, USA)), using a level of significance of $P<0 \cdot 05$. Results were defined as 'comparable' if $P>0 \cdot 05$.

\section{Results}

A representative HPLC chromatogram demonstrating plasma separation of lycopene isomers in human plasma is shown in Fig. 1. Results were calculated as total lycopene, including (all-E)-, (13Z)-, (5Z,9'Z)-, (9Z)-, (5Z,9Z)- and (5Z)-lycopene as well as any not yet identified $(Z)$-isomer of lycopene and

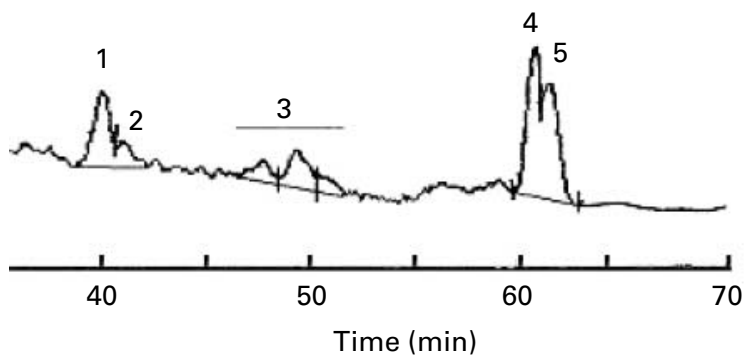

Fig. 1. HPLC chromatogram $(450 \mathrm{~nm})$ of lycopene isomers in human plasma by employing a gradient system of methanol and methyl tert-butyl ether. For details of the chromatographic conditions, see p. 735. For peak identification, see Fig. 2. the contents of the isomers separately. The contents of several isomers of lycopene are shown in Fig. 2. The lycopene concentrations of tomatoes, tomato juice and tomato purée used in the present study are presented in Table 1. (all-E)-Lycopene is the predominant isomer in each tomato product, accounting for $90-95 \%$ of total lycopene in tomatoes, $95-98 \%$ in tomato juice and $92-94 \%$ in tomato purée.

\section{Total lycopene}

Total lycopene plasma levels of the three groups of volunteers are shown in Fig. 3. Basal mean lycopene levels of all groups were in a comparable range $(P>0.05)$ between 0.57 and $0.78 \mu \mathrm{mol} / \mathrm{l}$. After the 2 -week diet with low lycopene intake, the total plasma lycopene concentration decreased $(P<0.05)$ to $45-62 \%$ of the basal values. The total lycopene plasma levels were significantly enhanced $(P<0.05)$ relative to the depleted state from 0.25 (SD 0.14) to 0.39 (SD 0.23) $\mu \mathrm{mol} / \mathrm{l}$ after 1 week of supplementation with tomatoes. Tomato juice also led to significantly $(P<0.05)$ increased lycopene plasma levels after 1 week of supplementation from 0.43 (SD $0 \cdot 15$ ) to 0.61 (SD $0 \cdot 17) \mu \mathrm{mol} / \mathrm{l}$. The total lycopene plasma levels remained nearly stable during the next 3 weeks of supplementation. Supplementation with tomato purée led to significantly enhanced $(P<0.05)$ plasma levels of lycopene after 2 weeks of intervention $(0.37$ (SD 0.19$)$ to 0.74 (SD $0 \cdot 24) \mu \mathrm{mol} / \mathrm{l}$ ). After 4 weeks of intervention with tomato products the increase of total lycopene in plasma was comparable $(P>0.05)$ for the three food matrices investigated. The total lycopene plasma levels at T4 of all groups $(0.53-0.81 \mu \mathrm{mol} /$ 1) were not significantly different $(P>0.05)$ from the basal levels $(\mathrm{T}-2)$.

\section{Isomers of lycopene}

The plasma levels of the several isomers of lycopene are shown in Fig. 2. The two major lycopene isomers in plasma of all volunteers were (all-E)- and (5Z)-lycopene. Decreases and increases in contents of both (Z)- and (all-E)-isomers of lycopene led to changes in concentrations of total lycopene within all intervention trials. Looking at alterations of the concentrations of the different $(Z)$-isomers of lycopene, only the (13Z)-lycopene showed significantly lower concentrations in plasma after intervention with tomatoes compared with tomato juice and tomato purée. The other lycopene isomers did not show significant $(P>0.05)$ differences among the three groups. The ratios of the sum of all evaluated lycopene $(Z)$-isomers:(all-E)-lycopene were used for assessment of isomer changes in plasma. The (Z)-lycopenes:(all-E)-lycopene isomer ratio was reversed during the study for all groups. The percentages of diverse lycopene isomers are shown in Table 2. Plasma isomer concentration showed an approximately 60:40 ratio of $(Z):($ all-E) at the start of the study. After a 2-week depletion period during which the participants consumed a diet low in lycopene, the ratios had changed. A decrease in the (all-E)-configuration to approximately $30 \%$ of total lycopene and a compensatory increase of the $(Z)$-isomers to $70 \%$ was observed. After 4 weeks of dietary intervention with tomato juice $(63 \%(Z) ; 37 \%($ all-E)) and tomato purée $(61 \%(Z) ; 39 \%($ all-E $))$ isomer ratios returned to those 

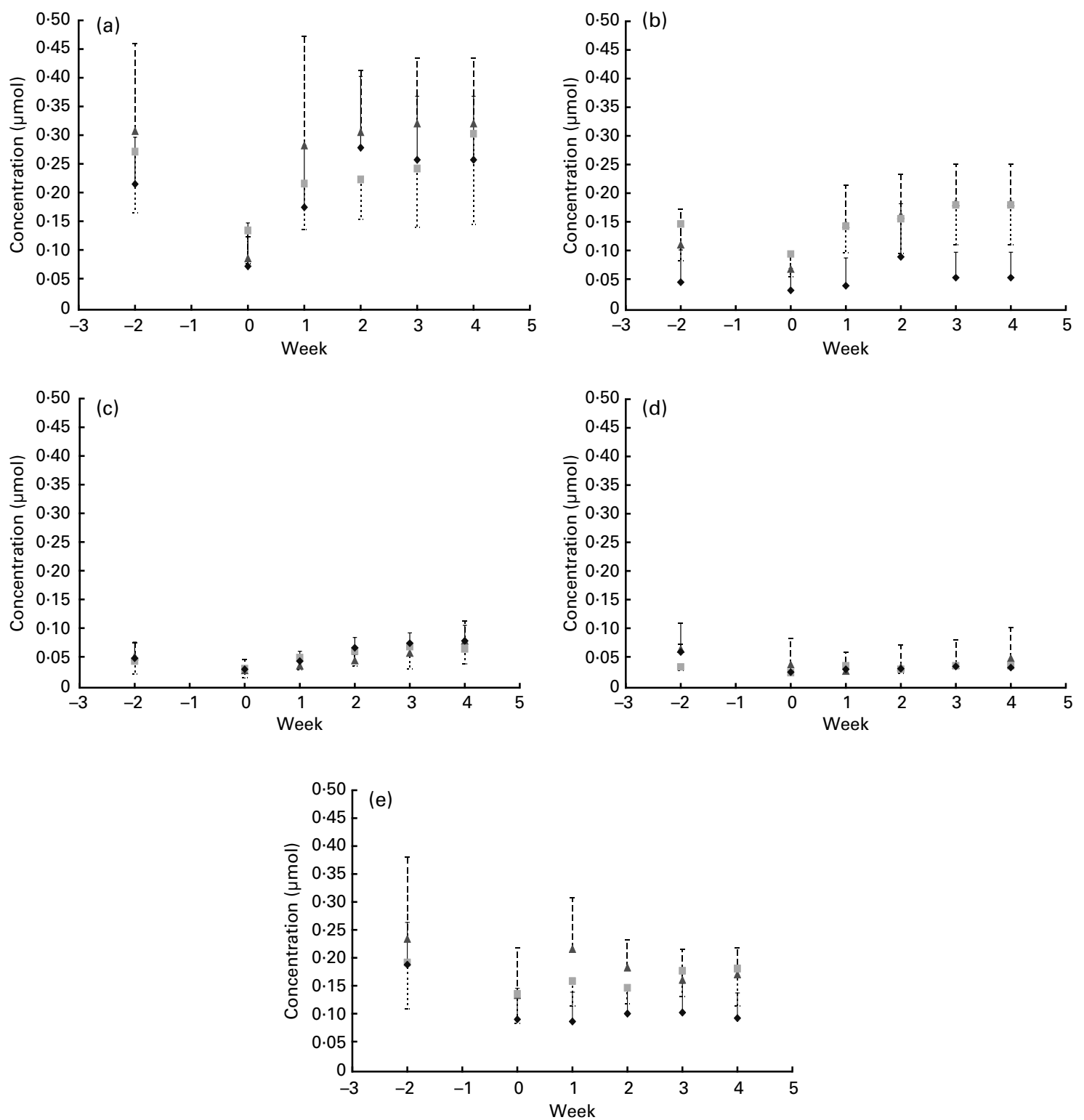

Fig. 2. Lycopene isomers in plasma of human subjects consuming tomatoes $(\bullet)$, tomato juice $(\square)$ or tomato purée $(\boldsymbol{\Delta})$ for 4 weeks after a 2 -week depletion period. (a) (all-E)-Lycopene, peak 4; (b) (13-Z)-lycopene, peak 1; (c) (Z)-lycopene, peak 2; (d) (5Z,9'Z) + (9Z) + (5Z,9Z)-lycopene, peak 3; (d) (5Z)-lycopene, peak 5. Values are means, with standard deviations represented by vertical bars. For details of subjects and procedures, see $p .734$.

observed at the start of the study. After 4 weeks of intervention with raw tomatoes the $(Z):($ all-E) ratio was 50:50.

\section{Ascorbic acid and tocopherols}

The contents of the antioxidant vitamins ascorbic acid and tocopherols in plasma did not change significantly $(P>0.05)$ during the depletion period and were not affected by 4 weeks of supplementation with tomatoes or tomato products (data not shown).

\section{Discussion}

In the present study, volunteers ingested $12.5 \mathrm{mg}$ lycopene/d from tomatoes, tomato juice and tomato purée. This is approximately a tenfold higher dose than those described in the German National Food Consumption Survey (Pelz et al. 1998). This high lycopene amount was chosen to guarantee sufficient detection of minor compounds in plasma such as some (Z)-lycopene isomers. Furthermore, $145-320 \mathrm{~g}$ tomatoes, $94-101 \mathrm{~g}$ tomato juice and $25-28 \mathrm{~g}$ tomato purée daily are in accordance with consumable amounts of tomato products.

At the end of a 2-week depletion period with a diet low in lycopene, the total plasma lycopene concentration decreased significantly $(P<0.05)$ to $53 \%$ (range $45-62 \%)$ of the basal values. Other publications have reported comparable plasma lycopene clearance rates (Böhm \& Bitsch, 1999; Allen et al. 2003).

The daily consumption of commercially available tomatoes and tomato products rapidly and significantly increases blood lycopene concentrations. The present study showed 


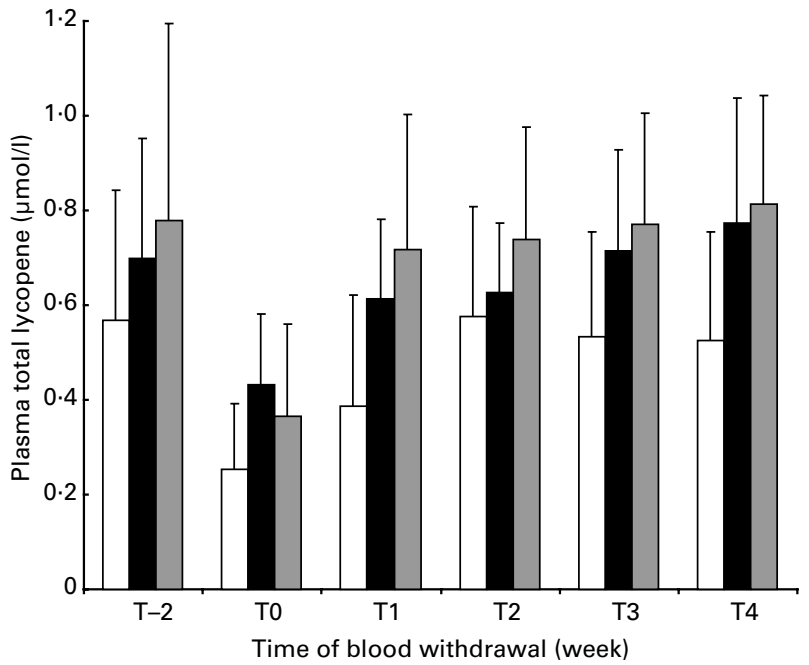

Fig. 3. Plasma total lycopene concentration over time in subjects consuming daily portions of tomatoes $(\square)$, tomato juice $(\square)$ or tomato purée ( $\square$ ) for 4 weeks after a 2-week depletion period. Values are means, with standard deviations represented by vertical bars. For details of subjects and procedures, see p. 734.

a significant increase $(P<0.05)$ in plasma total lycopene over the first 2-week period of intervention in all groups followed by an apparent plateau. This plateau effect was reported previously (Paetau et al. 1998) in response to continued doses of lycopene supplements or tomato juice. The comparable increase $(P>0.05)$ of lycopene in plasma for the three food matrices is in contrast to former investigations, supplementing volunteers with $5 \mathrm{mg}$ lycopene/d comprising tomatoes, tomato juice and oleoresin capsules (Böhm \& Bitsch, 1999). That study showed better intestinal absorption of lycopene from tomato juice and oleoresin capsules than from raw tomatoes. The difference between the present study and the former investigations is the daily dosage of lycopene, which is higher within the present trial $(12.5$ v. $5 \mathrm{mg} / \mathrm{d})$. Higher intestinal absorption of lycopene from processed tomato products compared with unprocessed tomatoes was also described in other studies (Gärtner et al. 1997; Porrini et al. 1998; van het Hof et al. 2000). The first steps of the carotenoid absorption include disruption of the food matrix and the subsequent release of the carotenoids from this matrix and from protein complexes (Britton, 1995). A greater increase in plasma lycopene was demonstrated following consumption of homogenised tomatoes compared with whole tomatoes, indicating that lycopene from disrupted cells is more available for absorption (Shi \& Le Maguer, 2000; van het Hof et al. 2000). In the present study, an increased bioavailability may have resulted due to cutting the tomatoes into small pieces. It is also known that intestinal absorption is strongly affected by the fat content of the diet, fats being essential for carotenoid extraction from the aqueous bulk of the food and the formation of mixed micelles via which the carotenoids are absorbed by enterocytes and transferred to the tissues via plasma lipoproteins (Borel et al. 1996; Parker, 1997). Some participants made a tomato salad from the fresh tomatoes and dressed it with oil. Therefore, it may be assumed that the tomato group consumed more fat than the groups ingesting tomato juice or tomato purée. For this reason, an increased lycopene bioavailability for tomatoes is possible. The type of lipids consumed may also influence carotenoid absorption (Stahl \& Sies, 1992; Borel et al. 1996). Future studies are necessary to assess many of the complexities of lycopene bioavailability.

Lycopene exists in multiple isomeric forms. The majority $(>90 \%)$ of lycopene in tomatoes and tomato products is (all-E)-lycopene. After ingestion of lycopene-containing food, (Z)-isomers constitute more than $50 \%$ of the total lycopene in human plasma. In the present study, (all-E)-lycopene $(39-40 \%)$ and (5Z)-lycopene $(27-34 \%)$ are the predominant

Table 2. Relative contents of lycopene isomers over time in subjects consuming daily portions of tomatoes or tomato products for 4 weeks after a 2-week initial depletion period

(Mean values and standard deviations)

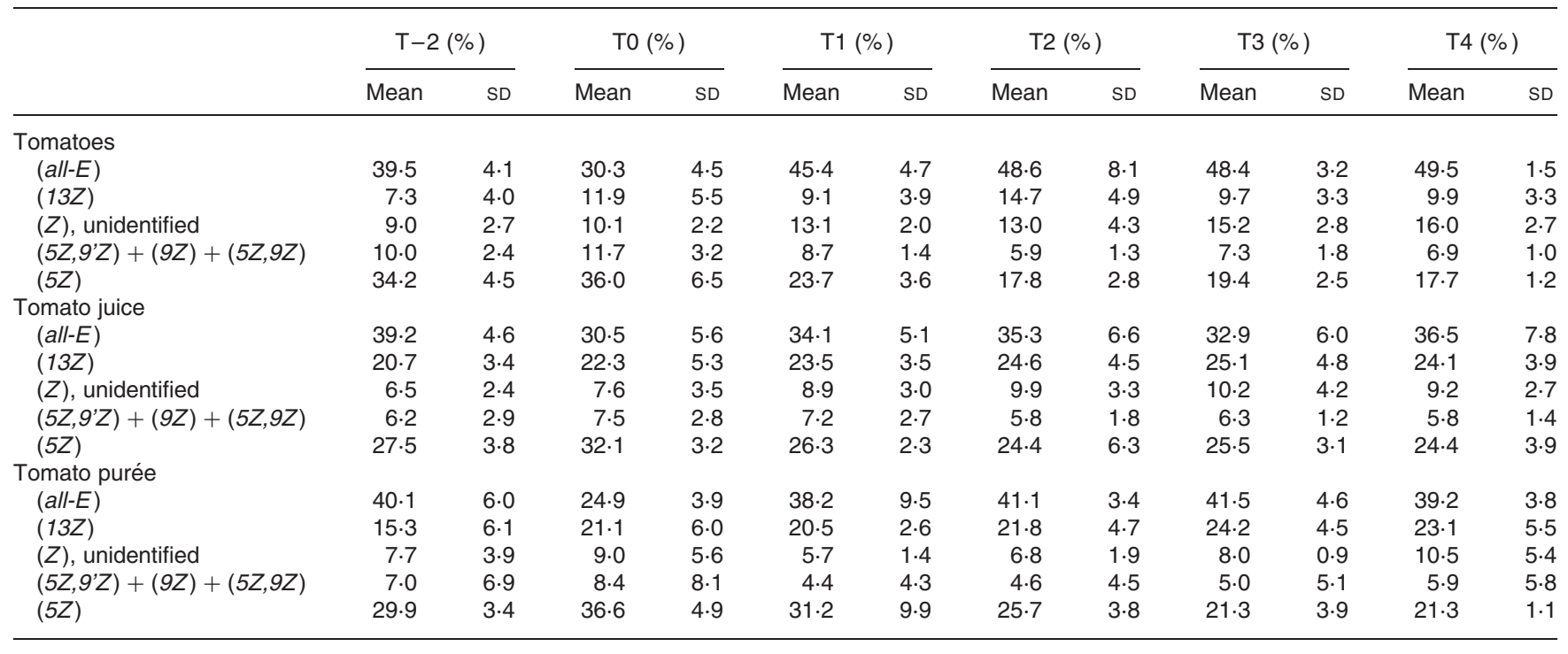

For details of subjects and procedures, see p. 734. 
isomers at baseline, a finding consistent with other reports (Clinton et al. 1996; Schierle et al. 1997; Holloway et al. 2000; Richelle et al. 2002). During the depletion period, a significant change in the $(Z)$ : (all-E) isomeric ratios from approximately $60 \%(Z), 40 \%$ (all-E) before the study to $70 \%(Z)$, $30 \%$ (all-E) after 2 weeks on a lycopene-free diet was observed. Comparable changes in the $(Z):($ all-E) ratios of lycopene in human plasma were described in another study. Hadley et al. (2003) showed a significant decrease of (all$E$ )-lycopene as a percentage of plasma total lycopene isomers from 44.4 (SEM 1.2) \% to 39.6 (SEM 1.2) \%, whereas total (Z)isomers increased from 55.6 (SEM 1.2) \% to 60.4 (SEM 1.2) \% during a 1 -week washout period. The percentage of (all-E)lycopene also decreased after 3 weeks on a lycopene-free diet in a study by Edwards et al. (2003). Conversely, a study by Müller et al. (1999) did not find a significant difference in the (Z):(all-E)-lycopene ratio during a 2-week washout period. This decrease in the relative proportion of $(E)$-lycopene of total lycopene in plasma may be a result of several simultaneous processes, including a more rapid clearance of (all-E)-lycopene, a greater tissue uptake of (all-E)-lycopene or conversion to $(Z)$-isomers in the human body. In addition, the possible mobilisation of lycopene from tissue stores where lycopene is predominantly found in the cis form may contribute to a relative increase in the plasma $(Z)$-isomer pool.

After 4 weeks of intervention with tomato juice and tomato purée (with the exception of tomatoes) the (Z):(all-E)-lycopene ratio returned to those observed at the beginning of the study. Other studies confirmed these findings. Holloway et al. (2000) reported that (all-E)-lycopene increased to 40-45\% of plasma lycopene after 2 weeks of supplementation with $21 \mathrm{mg}$ lycopene/d comprising tomato paste. Similarly, the percentage of (all-E)-lycopene increased significantly from 30-32 at baseline to 44-46 after 3 weeks of intervention with watermelon juice (Edwards et al. 2003). However, Hadley et al. (2003) observed a decrease of the relative contents of (5Z)-lycopene in a study where sixty volunteers ingested $23-55 \mathrm{mg}$ lycopene/d comprising tomato products for $15 \mathrm{~d}$. The observations suggest that maintaining a stable $($ all-E):(Z) isomers ratio in the blood requires continued dietary intake of the (all-E) form being predominant in food. It is also possible that lycopene exists in plasma as a mixture of (all-E)- and (Z)-isomers of lycopene because this mixture is the thermodynamically most stable equilibrium of different geometric isomers.

Accumulating evidence in human subjects (Stahl \& Sies, 1992; Gärtner et al. 1997; Boileau et al. 2002) and in animal models (Boileau et al. 1999) supports the hypothesis that $(Z)$-lycopene isomers are preferentially absorbed to $(E)$ lycopene. This may be the result of a greater solubility of $(Z)$-isomers in mixed micelles and a lower tendency to aggregate (Britton, 1995). A study from Re et al. (2001) reported that a high percentage of $(Z)$-lycopene isomers is present in tissues because it is better absorbed than $(E)$-lycopene from the gastrointestinal tract. Therefore, the increase in plasma concentrations of $(Z)$-isomers following administration of products containing lycopene is not solely related to the content of dosed ( $Z$ )-lycopene isomers. The elevated content of different $(Z$ )-isomers in plasma may account for a longer residence time, which is in line with a longer half-life for $(Z)$-isomers compared with that of (all-E)-lycopene (Cohn et al. 2002). Alternative explanations are isomerisation of systemic available (all-E)-lycopene within the human body. Isomerisation of (all-E)-lycopene to (Z)-lycopene is likely to occur during digestion ( $\operatorname{Re}$ et al. 2001), but only after (all-E)-lycopene is released from the food matrix, in which it is fairly stable (Nguyen \& Schwartz, 1998). The presence of acid in the stomach is perhaps the most plausible cause of (Z)isomer formation, but this does not explain the diversity in the distribution of geometrical carotenoid isomers found in different organs of the body. A recent human intervention study showed that there was no significant $(E)-(Z)$ isomerisation of lycopene in the human stomach. The fact that lycopene $(Z)$-isomers are poorly transported by the chylomicrons and thus poorly absorbed strongly suggested that a $(E)-(Z)$ isomerisation of lycopene occurs in the human body at a postenterocyte level (Tyssandier et al. 2003). Future investigations are necessary to assess whether: (1) (Z)-lycopene isomers are preferentially absorbed in human subjects; (2) (all-E)-lycopene is converted into (Z)-isomers after absorption; (3) (Z)isomers of lycopene mobilised from body stores to plasma or (all-E)-lycopene is preferentially degraded in the plasma compared with (Z)-lycopene. It is supposed that a combination of several mechanisms occurs in the human body.

Regarding vitamin $\mathrm{C}$ and $\mathrm{E}$, no significant differences were observed in the plasma contents of ascorbic acid and tocopherols $(P>0.05)$ during the entire study period, although both vitamins were ingested with the tomatoes and tomato products. Tyssandier et al. (2004) also did not detect any change in plasma ascorbic acid and tocopherols in a study in which subjects ingested $96 \mathrm{~g}$ tomato purée/d for 3 weeks. The plasma concentrations of these micronutrients are mainly correlated with the dietary intake of these compounds, with tomatoes and tomato products contributing a minor part.

In conclusion, ingestion of $12.5 \mathrm{mg}$ lycopene/d for 4 weeks as tomatoes, tomato juice and tomato purée resulted in significantly increased plasma concentration of total lycopene. Under the conditions in the present study, lycopene appeared to be approximately equally bioavailable from the three commodities. Looking at alterations of the relative contents of the lycopene isomers, the $(Z)$ :(all-E)-lycopene isomer ratio was reversed during the study for all groups. A remarkable enrichment of the relative contents of $(Z)$-lycopene was observed during the depletion period. After dietary intervention with lycopene-rich products the isomer ratio regained a state comparable with those observed at the beginning of the washout period. Further investigations will clarify the process of isomerisation of lycopene in more detail.

\section{Acknowledgements}

DSM Nutritional Products, Basel, Switzerland, is gratefully acknowledged for supplying the carotenoid reference materials. The authors are indebted to H. Schmidt and I. Schmuck for their technical assistance and to T. Franke for withdrawal of blood. Finally, thanks are also given to all study participants.

\section{References}

Allen CM, Schwartz SJ, Craft NE, Giovannucci EL, De Groff VL \& Clinton SK (2003) Changes in plasma and oral mucosal lycopene isomer concentrations in healthy adults consuming standard servings of processed tomato products. Nutr Cancer 47, 48-56. 
Balz M, Schulte E \& Thier H-P (1992) Trennung von tocopherolen und tocotrienolen durch HPLC, (Separation of tocopherols and tocotrienols during HPLC). Fat Wis Technol 94, 209-213.

Bieri JG, Brown ED \& Smith JC (1985) Determination of individual carotenoids in human plasma by high performance liquid chromatography. J Liquid Chromatogr 8, 473-484.

Böhm V (2001) Use of column temperature to optimize carotenoid isomer separation by $\mathrm{C}_{30}$ high performance liquid chromatography. J Sep Sci 24, 955-959.

Böhm V \& Bitsch R (1999) Intestinal absorption of lycopene from different matrices and interactions to other carotenoids, the lipid status, and the antioxidant capacity of human plasma. Eur J Nutr 38, $118-125$.

Böhm V, Puspitasari-Nienaber NL, Ferruzzi MG \& Schwartz SJ (2002) Trolox equivalent antioxidant capacity of different geometrical isomers of alpha-carotene, beta-carotene, lycopene, and zeaxanthin. J Agric Food Chem 50, 221-226.

Boileau AC, Merchen NR, Wasson K, Atkinson CA \& Erdman JW (1999) Cis-lycopene is more bioavailable than trans-lycopene in vitro and in vivo in lymph-cannulated ferrets. J Nutr 129, 1176-1181.

Boileau TW, Boileau AC \& Erdman JW (2002) Bioavailability of alltrans and cis-isomers of lycopene. Exp Biol Med 227, 914-919.

Borel P, Grolier P, Armand M, Partier A, Lafont H, Lairon D \& Azais-Braesco (1996) Carotenoids in biological emulsions: solubility, surface-to-core distribution, and release from lipid droplets. J Lipid Res 37, 250-261.

Breinholt V, Lauridsen ST, Daneshvar B \& Jakobsen J (2000) Doseresponse effect of lycopene on selected drug-metabolizing and antioxidant enzymes in the rat. Cancer Lett 154, 201-210.

Britton G (1995) Structure and properties of carotenoids in relation to function. FASEB J 9, 1551-1558.

Clinton SK (1998) Lycopene: chemistry, biology, and implications for human health, and disease. Nutr Rev 56, 35-51.

Clinton SK, Emenhiser C, Schwartz SJ, Bostwick DJ, Williams AW, Moore BJ \& Erdman Jr JW (1996) Cis-trans lycopene isomers, carotenoids, and retinol in the human prostate. Cancer Epidemiol Biomarkers Prev 5, 823-833.

Cohen LA (2002) A review of animal model studies of tomato carotenoids, lycopene, and cancer chemoprevention. Exp Biol Med 227, $864-868$.

Craft NE, Brown ED \& Smith JC Jr (1988) Effects of storage and handling conditions on concentrations of individual carotenoids, retinal, and tocopherols in plasma. Clin Chem 34, 44-48.

DiMascio P, Kaiser S \& Sies H (1989) Lycopene as the most efficient biological carotenoid singlet oxygen quencher. Arch Biochem Biophys 274, 532-538.

Edwards AJ, Vinyard BT, Wiley ER, Brown ED, Collins JK, PerkinsVeazie P, Baker RA \& Clevidence BA (2003) Consumption of watermelon juice increases plasma concentrations of lycopene and beta-carotene in humans. $J$ Nutr 133, 1043-1050.

Etminan M, Takkouche B \& Caamano-Isorna F (2004) The role of tomato products and lycopene in the prevention of prostate cancer: a meta-analysis of observational studies. Cancer Epidemiol Biomarkers Prev 13, 340-345.

Ferruzzi MG, Nguyen ML, Sander LC, Rock CL \& Schwartz SJ (2001) Analysis of lycopene geometrical isomers in biological microsamples by liquid chromatography with coulometric array detection. J Chromatogr 760B, 289-299.

Fröhlich K, Conrad J, Schmid A, Bitsch R, Breithaupt DE \& Böhm V (2005) Isolation and structural elucidation of prominent geometrical isomers of lycopene. Carotenoid Sci $\mathbf{9}, 89$.

Gahler S, Otto K \& Böhm V (2003) Alterations of vitamin C, total phenolics, and antioxidant capacity as affected by processing tomatoes to different products. J Agric Food Chem 51, 7962-7968.

Gärtner C, Stahl W \& Sies H (1997) Lycopene is more bioavailable from tomato paste than from fresh tomatoes. Am J Clin Nutr 66, $116-122$.
Giovannucci E, Rimm EB, Liu Y, Stampfer MJ \& Willet WC (2002) A prospective study of tomato products, lycopene, and prostate cancer risk. J Natl Cancer Inst 94, 391-398.

Hadley CW, Clinton SK \& Schwartz SJ (2003) The consumption of processed tomato products enhances plasma lycopene concentrations in association with a reduced lipoprotein sensitivity to oxidative damage. J Nutr 133, 727-732.

Holloway DE, Yang M, Paganga G, Rice-Evans CA \& Bramley PM (2000) Isomerization of dietary lycopene during assimilation and transport in plasma. Free Radic Res 32, 93-102.

Karas M, Amir H, Fishman D, Danilenko M, Segal S, Nahum A, Koifmann A, Giat Y, Levy J \& Sharoni Y (2000) Lycopene interferes with cell cycle progression and insulin-like growth factor I signaling in mammary cancer cells. Nutr Cancer 36, $101-111$.

Klipstein-Grobusch K, Launer LJ, Geleijnse JM, Boeing H, Hofman A \& Witteman JC (2000) Serum carotenoids and atherosclerosis: The Rotterdam Study. Atherosclerosis 148, 49-56.

Levy J, Bosin E, Feldman B, Giat Y, Miinster A, Danilenko M \& Sharoni Y (1995) Lycopene is a more potent inhibitor of human cancer cell proliferation than either $\alpha$-carotene or $\beta$-carotene. Nutr Cancer 24, 257-266.

Müller H, Bub A, Watzl B \& Rechkemmer G (1999) Plasma concentrations of carotenoids in healthy volunteers after intervention with carotenoid-rich foods. Eur J Nutr 38, 35-44.

Nguyen ML \& Schwartz SJ (1998) Lycopene stability during food processing. Proc Soc Exp Biol Med 218, 101-105.

Paetau I, Khachik F, Brown ED, Beecher GR, Kramer TR, Chittams J \& Clevidence BA (1998) Chronic ingestion of lycopene-rich tomato juice or lycopene supplements significantly increases plasma concentration of lycopene and related tomato carotenoids in humans. Am J Clin Nutr 68, 1187-1195.

Parker RS (1997) Bioavailability of carotenoids. Eur J Clin Nutr 51, 86-90.

Pelz R, Schmidt-Faber B \& Heseker H (1998) Carotenoid intake in the German National Food Consumption Survey. Z Ernährungswiss 37, 319-327.

Porrini M, Riso P \& Testolin G (1998) Absorption of lycopene from single or daily portions of raw and processed tomato. Br J Nutr $\mathbf{8 0}$, $353-361$.

Rao AV \& Agarwal S (1999) Role of lycopene as antioxidant carotenoid in the prevention of chronic diseases: a review. Nutr Res 19, 305-323.

Re R, Fraser PD, Long M, Bramley PM \& Rice-Evans C (2001) Isomerization of lycopene in the gastric milieu. Biochem Biophys Res Commun 281, 576-581.

Richelle M, Bortlik K, Liardet S, Hager C, Lambelet P, Baur M, Applegate LA \& Offord EA (2002) A food-based formulation provides lycopene with the same bioavailability to humans as that from tomato paste. $J$ Nutr 132, 404-408.

Schierle J, Bretzel W, Bühler I, Faccin N, Hess D, Steiner K \& Schuep W (1997) Content and isomeric ratio of lycopene in food and human blood plasma. Food Chem 59, 810-814.

Seybold C, Fröhlich K, Bitsch R, Otto K \& Böhm V (2004) Changes in contents of carotenoids and vitamin $\mathrm{E}$ during tomato processing. J Agric Food Chem 52, 7005-7010.

Sharoni Y, Danilenko M, Dubi N, Ben-Dor A \& Levy J (2004) Carotenoids and transcription. Arch Biochem Biophys 430, 89-96.

Shi J \& Le Maguer M (2000) Lycopene in tomatoes: chemical and physical properties affected by food processing. Crit Rev Food Sci Nutr 40, 1-42.

Speitling A, Hüppe R, Kohlmeier M, Matiaske B, Stelte W, Thefeld W \& Wetzel S (1992) Methodological handbook, nutrition survey and risk factors analysis. In VERA Publications Series, pp. 103-105 [W Kübler, H-J Anders, W Heeschen and M Kohlmeier, editors]. Niederkleen, Germany: Wissenschaftlicher Fachverlag Dr Fleck vol. 1A. 
Stahl W \& Sies H (1992) Uptake of lycopene and its geometrical isomers is greater from heat-processed than from unprocessed tomato juice in humans. J Nutr 122, 2161-2166.

Stahl W, von Laar J, Martin HD, Emmerich T \& Sies H (2000) Stimulation of gap junctional communication: comparison of acyclo-retinoic acid and lycopene. Arch Biochem Biophys 373, $271-274$

Tang L, Lin T, Zeng X \& Wang J-S (2005) Lycopene inhibits the growth of human androgen-independent prostate cancer cells in vitro and in BALB/c nude mice. J Nutr 135, 287-290.

Tyssandier V, Feillet-Coudray C, Caris-Veyrat C, et al. (2004) Effect of tomato product consumption on the plasma status of antioxidant microconstituents and on the plasma total antioxidant capacity in healthy subjects. J Am Coll Nutr 23, 148-156.
Tyssandier V, Reboul E, Dumas J-F, Bouteloup-Demange C, Armand M, Marcand J, Sallas M \& Borel P (2003) Processing of vegetableborne carotenoids in the human stomach and duodenum. Am J Physiol 284, G913-G923.

van het Hof KH, de Boer BC, Tijburg LB, Lucius BR, Zijp I, West CE, Hautvast JG \& Weststrate JA (2000) Carotenoid bioavailability in humans from tomatoes processed in different ways determined from the carotenoid response in the triglyceride-richlipoprotein fraction of plasma after a single consumption and in plasma after four days of consumption. J Nutr 130, 1189-1196.

Zhang L-X, Cooney RV \& Bertram JS (1991) Carotenoids enhance gap junctional communication and inhibit lipid peroxidation in C3H/10T1/2 cells: relationship to their cancer chemopreventive action. Carcinogenesis 12, 2109-2114. 